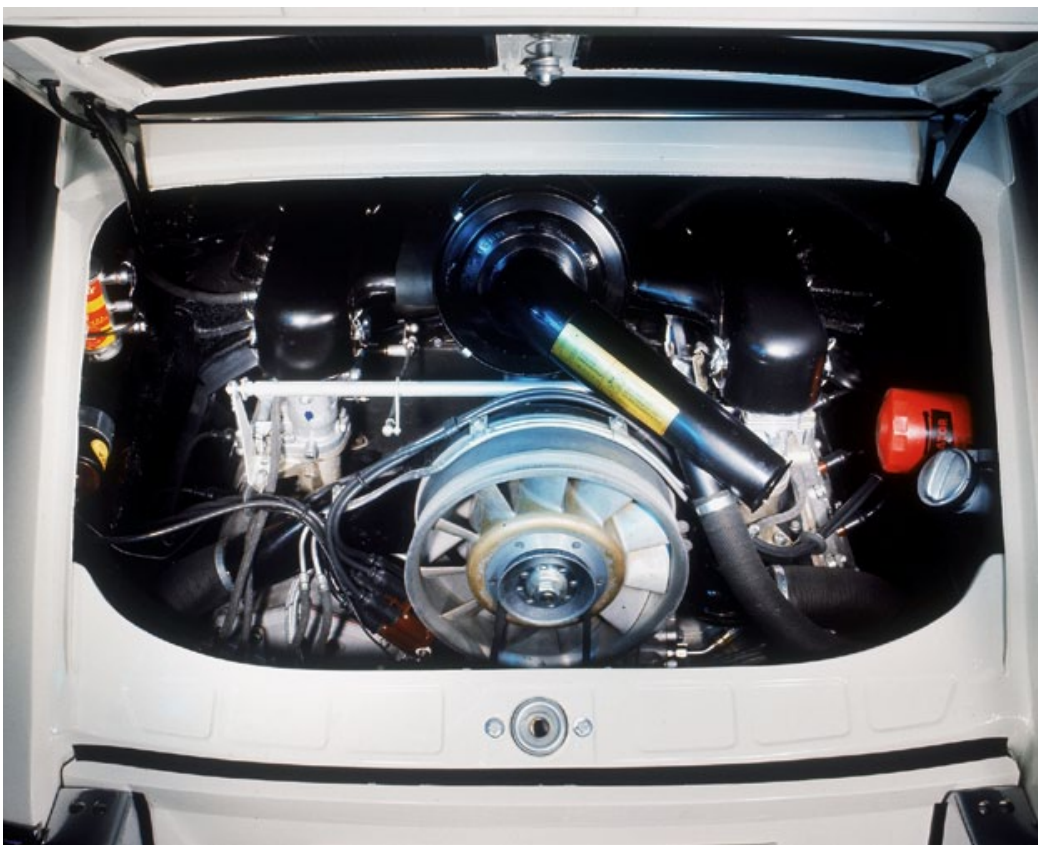

Serienstart des 901-Motors im Porsche 911 (Bild @ P Porsche)

Null-Serien-Motoren mit 96 kW beziehungsweise $118 \mathrm{~kW}$ zum Einsatz. Unterschiedliche Maßnahmen, wie zwei Weber-Dreifachvergaser statt sechs Solex-Überlaufvergaser, verschiedene Ventildurchmesser, geringere Ventilüberschneidung sowie überarbeitete Wärmetauscher lassen Porsche mit diesem 2,0-1-Aggregat Spielraum für unter- schiedliche Leistungsprofile. Das ab August 1968 lieferbare B-Modell verteilt nochmals drei unterschiedliche Motorentypen auf die Versionen „T“ (unverändert zum A-Modell, bis auf Magnesium-Kurbelwellengehäuse und eine stärkere Lichtmaschine mit $770 \mathrm{~W}$ ), ,E“ mit einer um $7,35 \mathrm{~kW}$ erhöhten Leistung - $103 \mathrm{~kW}$ bei 6500/min (wie vorhergehend „L“, jedoch

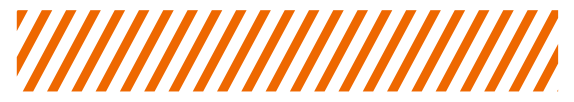

\section{ZITATE VON FERRY PORSCHE}

„Hätte ich damals gewusst, dass man den Motor (Typ 901) sogar bis drei Liter bei unverminderter Zuverlässigkeit, auch im Renneinsatz, vergrößern konnte, hätte ich bestimmt gesagt, der Motor sei unnötig groß und schwer, und ich hätte meinen Technikern gesagt, sie sollten inn kleiner machen. Jetzt bin ich froh, dass ich es nicht wusste."

„Im Laufe meines Lebens hat die Technik große Schritte zur Erleichterung und Verbesserung der Qualität unseres Lebens gemacht. Als Kind erlebte ich den Beginn des Automobilzeitalters; selbst aber fuhr ich noch mit dem Pferdewagen zur Schule."

„..., denn nur ein gutes Team konnte diese Leistung vollbringen."

\section{|||||||||||||||||||||||||||}

Der legendäre Schweizer Rennfahrer Herbert Müller auf dem Carrera mit 2,14---Turbomotor, 1974 (Bild @ Porsche)
Der schmal wirkende Porsche 911 Targa (G-Modell ab 1974) neben einem Serien-Turbo-Carrera und die dazugehörigen Motoren (Bild $\odot$ Porsche)

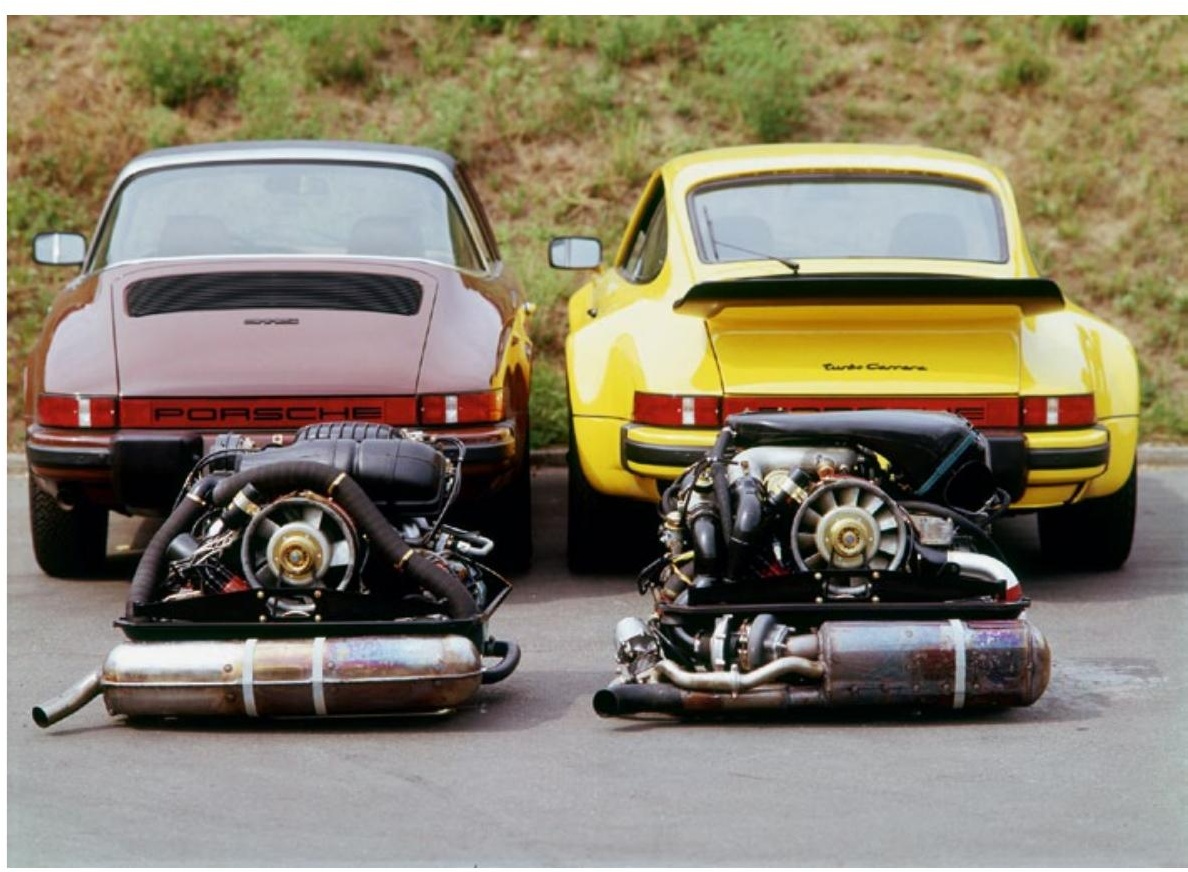

